\title{
Tuberous sclerosis: a syndrome of incomplete tumor suppression
}

\author{
Todd McCall, M.D., Steven S. Chin, M.D., Ph.D., Karen L. Salzman, M.D., \\ AND DANIEL W. Fults, M.D.
}

Departments of Neurosurgery, Pathology, and Radiology, University of Utah School of Medicine, Salt Lake City, Utah

\begin{abstract}
Tuberous sclerosis (TS) is a congenital neurocutaneous syndrome (or phacomatosis) characterized by widespread development of hamartomas in multiple organs. For affected individuals, neurological and psychiatric complications are the most disabling and lethal features. Although the clinical phenotype of TS is complex, only three lesions characterize the neuropathological features of the disease: cortical tubers, subependymal nodules, and subependymal giant cell astrocytomas. The latter is a benign brain tumor of mixed neuronal and glial origin. Tuberous sclerosis is caused by loss-of-function mutations in one of two genes, TSC1 or TSC2. The normal cellular proteins encoded by these genes, hamartin and tuberin, respectively, form a heterodimer that suppresses cell growth in the central nervous system by dampening the phosphatidylinositol 3-kinase signal transduction pathway. The authors review the clinical and neuropathological features of TS as well as recent research into the molecular biology of this disease. Through this work, investigators are beginning to resolve the paradoxical findings that malignant cancers seldom arise in patients with TS, even though the signaling molecules involved are key mediators of cancer cell growth.
\end{abstract}

\section{KEY WORDS • tuberous sclerosis • hamartoma • giant cell astrocytoma • hamartin • tuberin}

\section{OVERVIEW}

Tuberous sclerosis is a congenital neurocutaneous syndrome (or phacomatosis) characterized by widespread development of hamartomas in multiple organs. The French neurologist Désiré-Magloire Bourneville coined the term "tuberous sclerosis" in 1880 when he described the brain lesions found on postmortem examination of a 15 -year-old patient who had suffered seizures since infancy as well as mental retardation and hemiplegia. Tuberous sclerosis has an incidence of 1 in 6000 to 1 in 10,000 live births, with no ethnic clustering. ${ }^{24,40,68}$ Approximately two thirds of cases are sporadic; that is, affected individuals have no family history of the disease. ${ }^{3,25,68,76}$ Familial cases show an autosomal-dominant pattern of inheritance. The cloning of two different disease-causing genes (TSC1 and TSC2) has accelerated our understanding of the molecular pathogenesis of TS. Control of cell growth in the central nervous system is markedly perturbed in TS, but malignant brain tumors

Abbreviations used in this paper: ATP = adenosine 5'-triphosphate; IGF = insulin-like growth factor; IRS-1 = insulin receptor substrate-1; $\mathrm{MR}=$ magnetic resonance; $\mathrm{mRNA}=$ messenger RNA; mTOR $=$ mammalian target of rapamycin; PIP $_{2}=$ phosphatidylinositol 4,5-bisphosphate; $\mathrm{PIP}_{3}=$ phosphatidylinositol 3,4,5-trisphosphate; PI3K = phosphatidylinositol 3-kinase; SEGA = subependymal giant cell astrocytoma; $\mathrm{SEN}=$ subependymal nodule; $\mathrm{TS}=$ tuberous sclerosis; TSC $=$ TS complex. rarely occur. Nevertheless, this syndrome is a topic of clinical relevance to neurosurgeons because TS-related spaceoccupying lesions and intractable epilepsy may require timely surgical intervention.

\section{Clinical Pathology of the TSC}

The characteristic lesions of TS are hamartomas, which are congenitally misplaced groups of cells that form disorganized, tumor-like masses. Hamartomas occur in the brain (discussed later), kidneys, lung, heart, eyes, and skin. ${ }^{2}$ Skin hamartomas include facial angiofibromas (also known as adenoma sebaceum), subungual fibromas, and shagreen patches. ${ }^{26,84}$ The growth rate of visceral hamartomas can accelerate spontaneously to create expanding tumors (SEGAs of the brain, angiomyolipomas of the kidney, lymphangioleiomyomatosis of the lung, and rhabdomyomas of the heart). On histopathological examination, these tumors are almost always benign. The molecular signals that trigger this transition from quiescent hamartoma to enlarging tumor are not known. Surprisingly, patients with TS rarely present with malignant neoplasms even though they have numerous hamartomas and benign tumors, which are considered premalignant lesions. The most common malignant tumor associated with TS is renal cell carcinoma. ${ }^{1}$

The clinical presentation of TS is determined by the spe- 
cific organs affected. The severity of presenting symptoms is highly variable, ranging from minor skin lesions to intractable epilepsy and debilitating cognitive impairment. The classic symptom triad of adenoma sebaceum, epilepsy, and mental retardation comprised the first diagnostic criteria for TS. In 1998, the National Institutes of Health convened a consensus conference to standardize diagnostic criteria for the TSC. ${ }^{40,72}$ The published set of criteria was composed of clinical and radiographic features, which were divided into major and minor categories (Table 1). A definitive diagnosis of TS requires that a patient present with two of the major criteria shown in Table 1, or one major and two minor criteria. Notably, certain clinical signs that once were regarded as pathognomonic for TS, like mental retardation and epilepsy, are now considered nonspecific. Furthermore, no single criterion, found either clinically or radiographically, is present in all patients.

For affected individuals, neurological and psychiatric symptoms are the most disabling features. ${ }^{22,83}$ In fact, neurological complications are the leading cause of death for patients with TS, followed by renal disease and pulmonary lymphangioleiomyomatosis. ${ }^{16}$ The most common neurological symptoms are seizures, mental retardation, autism, hyperactivity, spastic paralysis, involuntary movements, ataxia, dementia, and ophthalmoplegia. ${ }^{10,26,38,82}$ More than $75 \%$ of patients suffer from seizures, and $68 \%$ have mild to severe cognitive impairment. ${ }^{39,56}$ As a general rule, larger and more numerous cortical tubers are associated with earlier seizure onset and more severe mental retardation..$^{26}$ The types of seizures found in patients with TS are highly variable and include tonic-clonic, atonic, myoclonic, atypical absence, partial, and partial complex seizures. ${ }^{86}$

\section{Neuropathology of TS: Hamartomas in the Brain}

Although the clinical phenotype of TS is complex, only three lesions characterize the neuropathology of the disease: cortical tubers and SENs, both of which are hamartomas, and SEGAs, which are histopathologically benign neoplasms. All three lesions occur predominantly in the brain. Hamartomas in the spinal cord have been reported, ${ }^{57}$ but no lesions occur in the peripheral nervous system..$^{71}$ The fact that cortical tubers and SEGAs have been reported in spontaneously aborted fetuses indicates that the lesions of TS originate during fetal development. ${ }^{18}$

Cortical tubers occur in approximately $80 \%$ of patients

TABLE 1

Diagnostic criteria for TS

\begin{tabular}{ll}
\hline \hline \multicolumn{1}{c}{ Major Features } & \multicolumn{1}{c}{ Minor Features } \\
\hline $\begin{array}{l}\text { facial angiofibromas } \\
\text { ungual or periungual fibroma } \\
\text { hypomelanotic macules }\end{array}$ & $\begin{array}{l}\text { multiple pits in dental enamel } \\
\text { hamartomatous rectal polyps } \\
\text { bone cysts }\end{array}$ \\
shagreen patch & "migration tracts" \\
cortical tuber & gingival fibromas \\
SEN & nonrenal hamartoma \\
SEGA & retinal achromic patch \\
multiple retinal nodular hamartomas & "confetti" skin lesions \\
cardiac rhabdomyoma & multiple renal cysts \\
lymphangiomyomatosis & \\
renal angiomyolipoma & \\
\hline
\end{tabular}

with TS..$^{20}$ Grossly, they appear as hard, wide gyri with smooth, flat tops or as rounded nodules with rough surfaces ${ }^{64}$ Most cortical tubers occur in the frontal and parietal lobes, ${ }^{35,61,71}$ but some arise in the cerebellum, brainstem, and spinal cord. ${ }^{26,41,57}$ Microscopically, cortical tubers consist of interlacing fascicles of normal and abnormal neurons, astrocytes, and giant cells (Fig. 1A-C). Subependymal nodules are distributed along the sulcus terminalis throughout both lateral ventricles. ${ }^{19,32,36,44,78}$ Microscopically they resemble cortical tubers, except that SENs have a higher cellular packing density and sometimes contain polygonal and spindle-shaped epithelioid cells and mast cells (Fig. 1D)..$^{20,80}$

Giant cells (also known as balloon cells) are the neuropathological hallmarks of TS. They have prominent nuclei and nucleoli and abundant, glassy, eosinophilic cytoplasm (Fig. 1C and D). ${ }^{20}$ The origin of giant cells remains uncertain. Immunohistochemical studies have shown that these cells coexpress proteins normally found in neurons (neurofilament protein, Class III $\beta$-tubulin) and in astrocytes (glial fibrillary acidic protein, S100 protein) (Fig. 1E and F). ${ }^{11,18,35,45,65}$ Electron microscopy studies have shown that ultrastructural characteristics of neurons (lamellae of rough endoplasmic reticulum, dense-core granules) and astrocytes (glycogen granules, membrane-bound dense bodies) are found together in individual giant cells..$^{35,81,88}$ Taken together, these findings support the suggestion that giant cells might originate from mixed glioneuronal precursors.

Subependymal giant cell astrocytoma is the most common brain tumor associated with TS. It is detected in $6 \%$ of patients, most often presenting with seizures or hydrocephalus. ${ }^{26}$ It usually presents in the first two decades of life, occasionally in the early postnatal period..$^{87}$ Rarely has a SEGA been reported in an individual who did not meet the diagnostic criteria of TS. ${ }^{11}$ Although this type of tumor is histologically benign and grows slowly, malignant transformation and even massive hemorrhage have been reported. ${ }^{13,91}$

The cytoarchitecture of SEGAs is indistinguishable from that of SENs, except for the presence of mitotic figures in the tumors. Figure 1 shows the cytological features of a SEGA, including variable cellular packing density (panels $\mathrm{A}$ and $\mathrm{B}$ ), giant cells with interspersed mast cells (panels C and D), and coexpression of neuron-specific and astrocytespecific intermediate filament proteins (panels E and F). This similarity has fostered the idea that SEGAs arise by transformation of giant cells in preexisting SENs, as reviewed by Gomez. ${ }^{26}$ An observation that remains unexplained by this hypothesis is that SEGAs occur exclusively at the foramen of Monro, although nodules are distributed throughout the lateral ventricles.

\section{Radiographic Features: Varied Densities and Intensities}

Historically, intracranial calcification on skull x-ray films was the first radiographic sign of TS..$^{59}$ This appearance was due to dystrophic calcification in cortical tubers and SENs. On early pneumoencephalograms, SENs could be seen protruding into the lumen of the lateral ventricle, giving the appearance of molten candle wax ("candle gutterings"). Modern computerized tomography scanning detects brain calcification in 50 to $80 \%$ of patients (Fig. 2A). Subependymal nodules are usually densely calcified, whereas cortical tubers show variable density, depending on the amount 


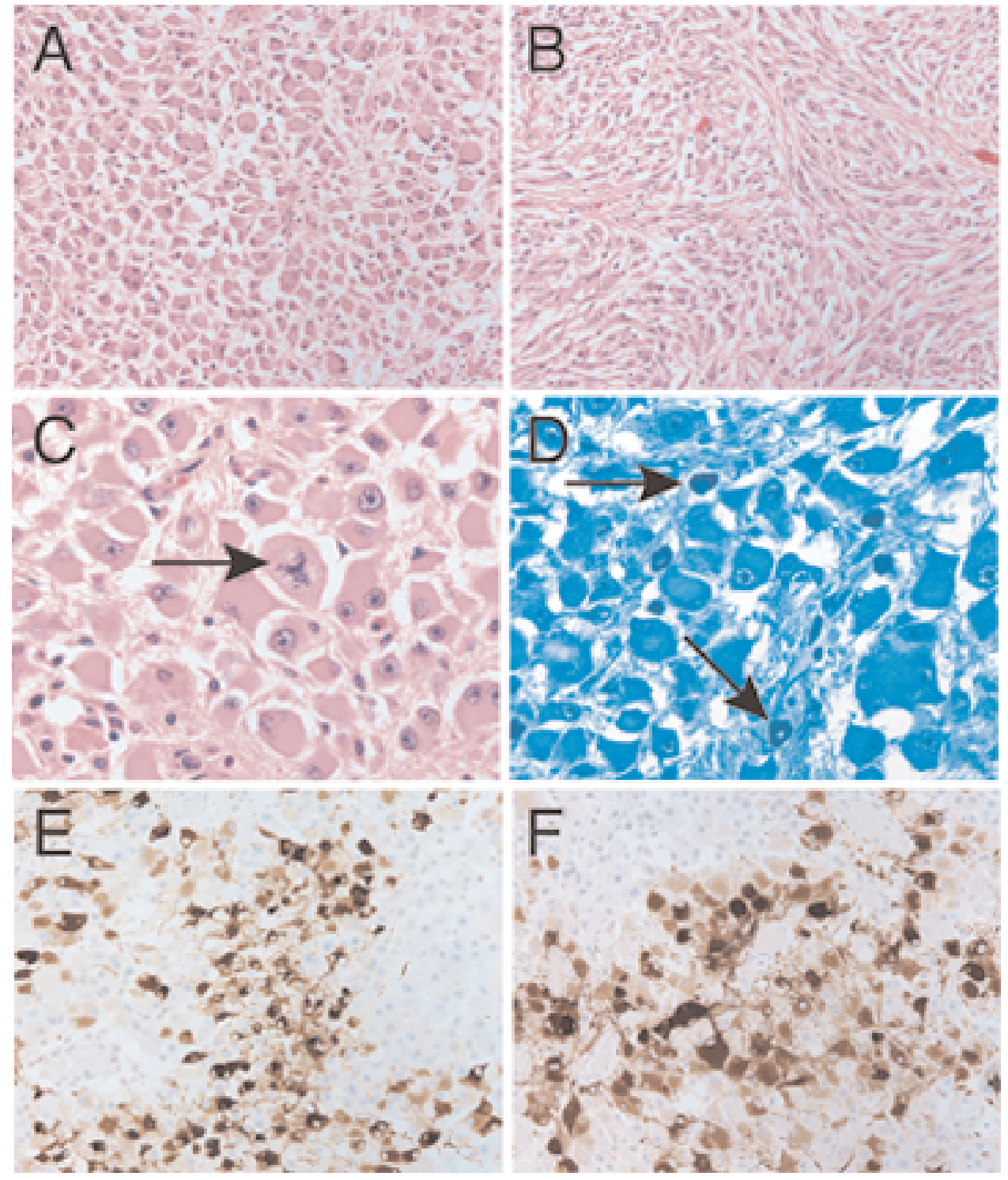

Fig. 1. Photomicrographs showing histopathological findings in a SEGA. A and B: Low-power photomicrographs showing loosely distributed giant cells (A) and densely packed, interlacing fascicles of spindle-shaped cells (B). H \& E, original magnification $\times 200$. C and D: High-power views showing morphological features of giant cells with abundant eosinophilic cytoplasm (C) and mitotic figures (arrow). Addition of toluidine blue (D) reveals darkly staining mast cells (arrows) interspersed among lightly staining giant cells. Original magnifications $\times 600$ (C) and $\times 400$ (D). $E$ and F: Immunoperoxidase staining shows coexpression of neurofilament protein (E) and glial fibrillary acidic protein (F). All sections are from a single patient's tumor specimen. Original magnifications $\times 200$.

of calcium present. ${ }^{37,63}$ On MR imaging, cortical tubers appear hyperintense on $\mathrm{T}_{2}$-weighted images (Fig. 2B). ${ }^{37} \mathrm{Sub}$ ependymal nodules appear slightly more intense than deep gray matter on $\mathrm{T}_{1}$-weighted images. Their signal intensity on $\mathrm{T}_{2}$-weighted MR images varies from patient to patient but is typically hypointense because of the calcification. The appearance of SEGAs on neuroimages closely resembles that of SENs, except that the tumors are larger and they enhance brightly after delivery of intravenous contrast agents (Fig. 2C). In addition, SEGAs are invariably located at the foramen of Monro. Advances in brain imaging have revealed that patients with TS often exhibit developmental anomalies that are not unique to the syndrome, such as agenesis of the corpus callosum, heterotopias, transmantle cor- tical dysplasia, and schizencephaly. ${ }^{19,44,90}$ Transmantle cortical dysplasia appears on MR images as radial bands of abnormal signal intensity extending from periventricular to subcortical regions of the cerebral hemispheres (Fig. 2D). Radial bands sometimes interconnect cortical tubers and SENs. These lesions are typically $T_{1}$ hyperintense and $T_{2}$ hypointense in infants and become $\mathrm{T}_{1}$ hypointense and $\mathrm{T}_{2}$ hyperintense in older children and adults. ${ }^{8}$ Radial bands are thought to represent a disturbance in the normal migration of neural progenitor cells from the ventricular germinal matrix to the cerebral cortex during brain development. ${ }^{5,12}$

The TSC Genes Encode Tumor Suppressors

An extensive body of evidence indicates that TS is 

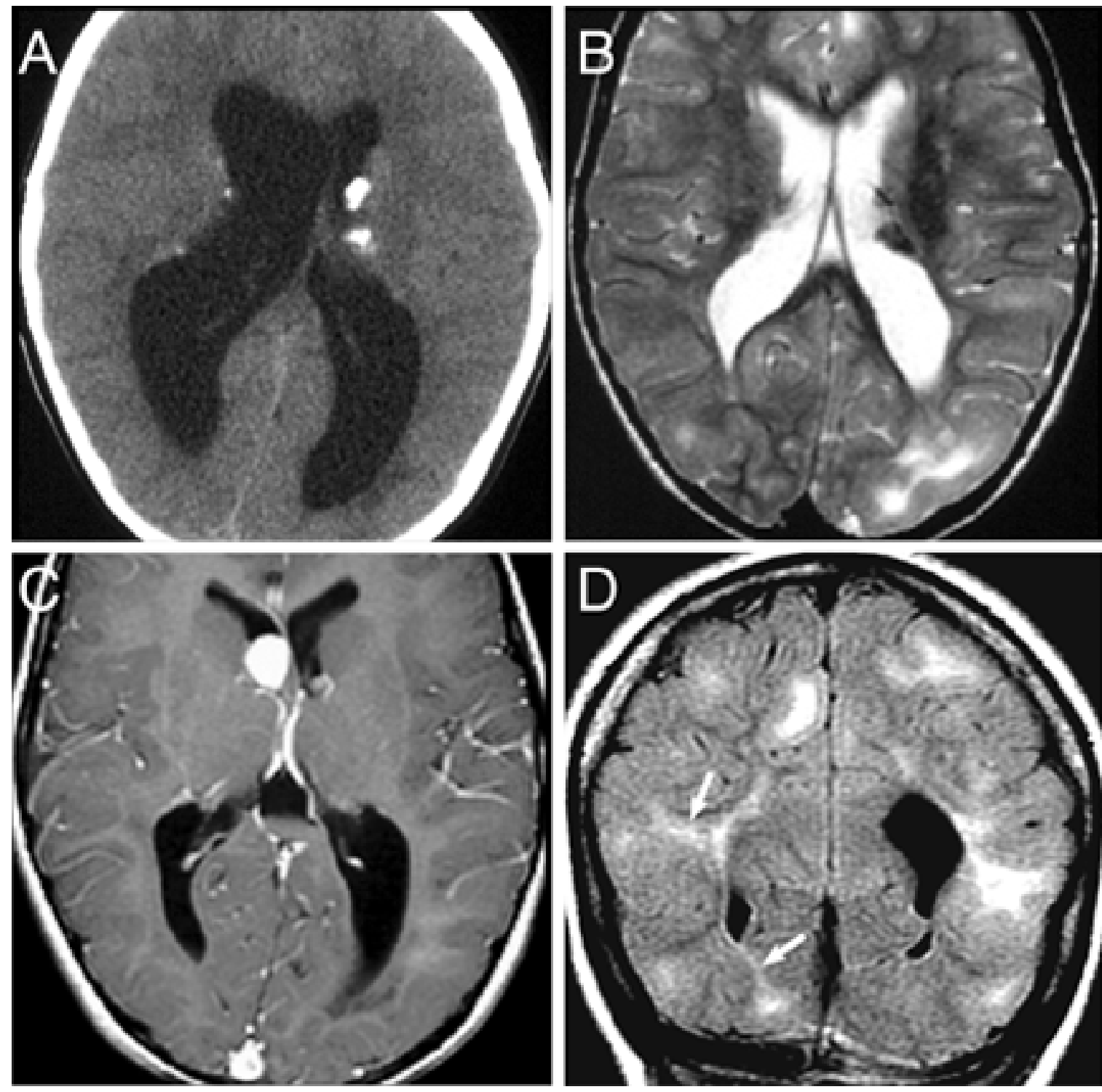

Fig. 2. Neuroimages showing the features of TS. A: A computerized tomography scan demonstrating calcified SENs. B: Hyperintense multifocal cortical tubers revealed on $\mathrm{T}_{2}$-weighted MR image. C: Gadolinium-enhanced $\mathrm{T}_{1}$ weighted MR image revealing a SEGA obstructing the right foramen of Monro. D: A fluid-attenuated inversion-recovery MR image showing radial bands (arrows) and multiple cortical tubers.

caused by loss-of-function mutations in one of two genes, TSC1 located on human chromosome $9 \mathrm{q} 34$ or TSC2 located on 16p13. The proteins encoded by TSC1 and TSC2 are called hamartin and tuberin, respectively. A detailed review of the molecular genetics of TS, which contains an analysis of mutations compiled from 446 patients, has been published by Cheadle, et al. ${ }^{17}$ In familial cases of TS, the mutation frequency for TSCl and TSC2 is equal (50\% for each gene). In sporadic cases, TSC1 mutations are found in approximately 10 to $15 \%$ of patients and TSC 2 mutations are found in $70 \%$. In sporadic and familial cases combined, mutations in either TSC1 or TSC2 have been found in 75 to $90 \%$ of patients with TS. The absence of mutations in the remaining 10 to $25 \%$ of patients most likely reflects limitations in the sensitivity of mutation detection rather than the existence of other genes distinct from TSC1 and TSC2.
Several independent studies have shown close similarities between the phenotypic features associated with TSC1 and TSC2 mutations, suggesting that TS is a disease characterized by locus heterogeneity. ${ }^{66,70,89}$ Locus heterogeneity predicts that these two genes will encode proteins that function together in the same biochemical pathway. Indeed, hamartin and tuberin, the cellular proteins encoded by $T S C 1$ and TSC2, are now known to interact to suppress the PI3K signal transduction pathway, which will be discussed later. The results of other studies suggest that patients with TSC2 mutations have more disabling neurological impairments than those with TSC1 mutations. ${ }^{47,48,50,60}$ For example, a genotype-phenotype correlation in 224 patients showed that TSC1 mutations were associated with lower seizure frequency, milder cognitive impairment, fewer SENs and cortical tubers, less severe kidney and skin disease, and the 
Tuberous sclerosis: a syndrome of incomplete tumor suppression

absence of retinal hamartomas. ${ }^{23}$ Patients with TSC2 mutations may be more susceptible to aggressive renal tumors. ${ }^{1}$

Several lines of evidence indicate that TSC1 and TSC2 are tumor suppressor genes. Such genes encode proteins that function normally to inhibit cell growth. According to the Knudson ${ }^{53}$ two-hit model, an inherited (germline) mutation in one copy (allele) of a tumor suppressor gene predisposes an individual to tumor formation. A somatic mutation (second hit) that inactivates the remaining normal allele is required to initiate tumor formation. In this model, loss of both allelic copies of a tumor suppressor gene removes a physiological constraint to cell growth. The second hit is often a deletion of the chromosome region containing the tumor suppressor gene. A molecular signpost for a chromosome deletion is loss of heterozygosity in tumor DNA compared with an individual's normal DNA. Frequent loss of heterozygosity in a particular type of tumor indicates that a tumor suppressor gene important in the genesis of that tumor is present on the missing part of the chromosome.

Loss of heterozygosity for TSC1 and TSC2 has been reported in a wide variety of hamartomas and tumors resected in patients with TS, including renal angiomyolipomas, ${ }^{27,33,34}$ cortical tubers, ${ }^{15,28,79}$ and SEGAs. ${ }^{28,79}$ Approximately $50 \%$ of hamartomas have loss of heterozygosity for loci on chromosome 9q34, where TSC2 is located, and $10 \%$ have loss of heterozygosity for chromosome $16 \mathrm{p} 13$ loci, which are linked to TSC1..$^{15,79}$ The observation that mutations in these genes are usually nonsense, splicing, or frameshift mutations, which encode truncated nonfunctional proteins, is additional evidence that TSC1 and TSC2 are tumor suppressor genes. ${ }^{17}$ Furthermore, an immunohistochemical study of nine SEGAs showed that expression of both tuberin and hamartin was absent or barely detectable in eight cases. ${ }^{49}$ Interestingly, the tumor cells obtained in one patient with a TSC2 mutation showed no hamartin but abundant tuberin. Taken together, these observations support the concept that hamartomas and other tumors arise in patients with TS when inactivation of either hamartin or tuberin stimulates the growth of susceptible cells.

\section{Hamartin and Tuberin Integrate Growth Factor and Nutrient Signals in the Cell}

The proteins hamartin and tuberin, which are encoded by TSC1 and TSC2, bind to one another inside the cytoplasm to form a molecular complex that serves as a gate to control cell growth signals conveyed through the PI3K signal transduction pathway. As reviewed by Cantley, ${ }^{14}$ the PI3K pathway is a vital information system that governs many aspects of cell growth. In a review of the literature, Rowinsky ${ }^{75}$ has reported that the pathway is hyperactive in many types of malignant tumors. Detailed reviews focused on the hamartin/tuberin complex in PI3K signaling have been published by Hay and Sonenberg ${ }^{31}$ and by Inoki, et al. ${ }^{42}$ One vital function of the PI3K pathway is to transduce cell growth and survival signals conveyed by extracellular growth factors such as IGFs. Salient features of IGF-stimulated PI3K signaling are shown schematically in Fig. 3. When IGFs engage their cognate receptors on the cell surface, the activated tyrosine kinase receptors phosphorylate the cytoplasmic protein IRS-1, thereby creating a molecular docking site for the regulatory subunit of the enzyme PI3K. Conse- quent activation of the catalytic subunit of PI3K converts the membrane-bound phospholipid $\mathrm{PIP}_{2}$ to $\mathrm{PIP}_{3}$, which recruits the serine/threonine kinase Akt to the plasma membrane, where Akt is phosphorylated and thereby activated catalytically. The tumor suppressor protein PTEN dampens $\mathrm{PI} 3 \mathrm{~K}$ signaling by dephosphorylating $\mathrm{PIP}_{3}$, thereby preventing attachment of Akt to the plasma membrane.

A key downstream component of the PI3K pathway is the cellular protein mTOR. The best-described biochemical function of mTOR is its promotion of mRNA translation and hence stimulation of protein synthesis in the cell. Like Akt, mTOR is a serine/threonine kinase that becomes catalytically activated in response to $\mathrm{PI} 3 \mathrm{~K}$ signaling. Although mTOR is a direct phosphorylation substrate for Akt, evidence is mounting that the principal mechanism whereby Akt activates mTOR is not by direct phosphorylation, but rather by disruption of the hamartin/tuberin complex. In the model shown in Fig. 3, the hamartin/tuberin complex functions normally to suppress mTOR activity. Activated Akt phosphorylates tuberin, causing the hamartin/tuberin complex to dissociate. The result is disinhibition of mTOR and consequent stimulation of mRNA translation, protein synthesis, and cell cycle progression. Although Akt and mTOR are functionally coupled in the PI3K pathway, each of these proteins transduces cell signals through a unique set of downstream effector molecules.

In addition to relaying growth factor signals to the nucleus of the cell, mTOR functions as a nutrient sensor during cell metabolism. Under conditions of nutrient deprivation, intracellular levels of ATP and amino acids fall. In response, mTOR activity declines. This compensatory mechanism makes sense for cells because it enables them to shut down their energy-demanding processes, like protein synthesis, during nutritionally hard times. The biochemical reactions that couple intracellular ATP levels with mTOR activity are not fully understood, but tuberin clearly plays a role. When cells are in low-energy states, the enzyme adenosine monophosphate-activated protein kinase phosphorylates tuberin, and this phosphorylated form of tuberin protects cells from apoptotic death induced by energy deprivation..$^{43}$ Thus, hamartin and tuberin, by regulating mTOR, integrate two of the most important signals governing cell growth: growth factors and nutrients.

\section{Mouse Models Elucidate the Low Level of Malignant Transformation in TS}

Considering the fact that hamartin and tuberin apply the brakes in a signal transduction pathway that is frequently activated in many types of malignant tumors, it is surprising that lesions in patients with TS rarely become malignant. Mouse models of TS provide an explanation. Mouse embryos in which either the $T s c 1$ or the $T s c 2$ gene is completely knocked out fail to develop beyond midgestation because they suffer hypoplasia of the liver and enlargement of the heart. ${ }^{54,55,58,67}$ Mice that are heterozygous defective for $T s c 1$ or $T s c 2$ develop normally, but they are predisposed to renal adenomas, which progress at low frequency to malignant cancers. These mice also develop hepatic hemangiomas and peripheral angiosarcomas. Interestingly, brain lesions, which are so common in cases of TS in humans, do not occur in these mouse models.

When $T s c 2^{+/-}$mice are crossed with mice that are het- 


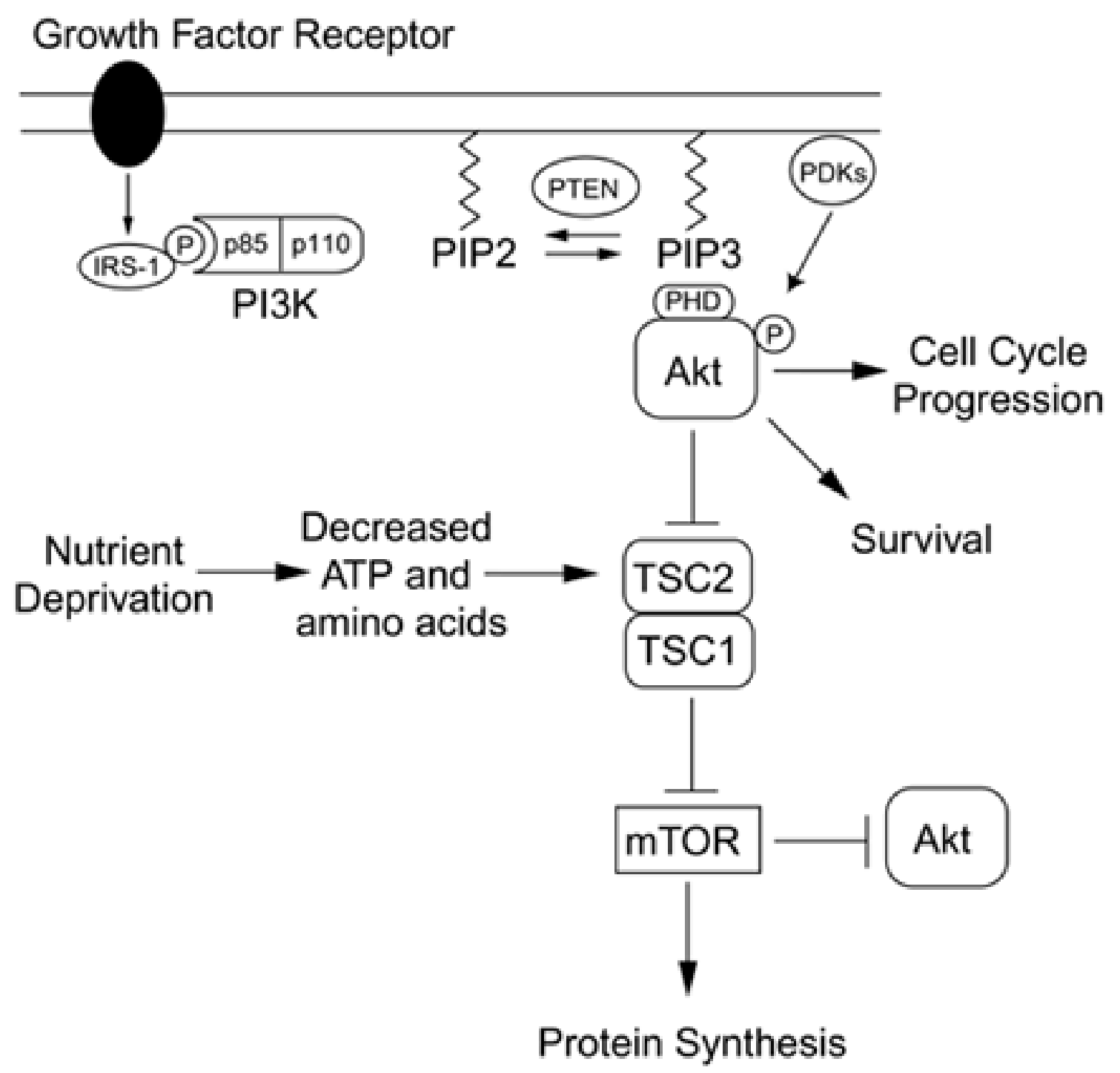

Fig. 3. Schematic drawing showing the PI3K/mTOR signal transduction pathway. When extracellular growth factors, such as IGF-1, engage and activate their receptors on the cell surface, the receptor tyrosine kinase phosphorylates IRS1, thereby creating a docking site for the regulatory subunit (p85) of PI3K. Consequent activation of the catalytic subunit (p110) converts membrane-bound $\mathrm{PIP}_{2}$ to $\mathrm{PIP}_{3}$, which recruits Akt to the plasma membrane through the pleckstrin homology domain (PHD) of Akt. The Akt becomes activated by phosphoinositide kinase-dependent kinases (PDKs). Activated Akt phosphorylates TSC2, thereby disrupting its association with TSC1. Dissociation of the TSC1/TSC2 complex derepresses mTOR, thereby stimulating protein synthesis. Nutrient deprivation inhibits protein synthesis by promoting TSC2mediated repression of mTOR. Activated mTOR imposes feedback inhibition on Akt signaling.

erozygous defective for the Pten tumor suppressor gene, the

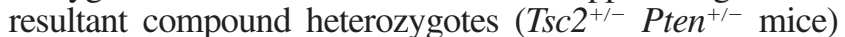
show an earlier onset and higher incidence of hepatic hemangiomas and peripheral angiosarcomas. ${ }^{62}$ Analysis of signaling molecules specifically regulated by Akt and mTOR shows that, in hepatic hemangiomas, signaling downstream of Akt is attenuated in the benign tumors found in $T s c 2^{+/-}$mice but is enhanced in the more aggressive tumors present in $T s c 2^{+/-} \mathrm{Pten}^{+/-}$mice. This suggests that loss of $T s c 2$ expression creates an inhibitory feedback loop, in which mTOR or one of its downstream effectors suppresses Akt signaling (Fig. 3). The Pten deficiency can overcome this inhibition by enabling PI3K signaling to increase cellular levels of activated Akt. Extrapolating these findings to TS in humans provides an explanation for the fact that malignant tumors rarely occur, although hamartomas, which result from aberrant cell growth control, are abundant. Tuberin deficiency simultaneously stimulates mTOR-mediated protein synthesis and inhibits Akt-mediated cell survival and proliferation (Fig. 3). The combined effect is to perturb cell growth control just enough to generate hamartomas but not sufficiently to induce malignant transformation.

\section{TREATMENT CONSIDERATIONS: EPILEPSY AND NEUROONCOLOGY}

The mainstay of seizure control for patients with TS is 
medical therapy with anticonvulsant drugs and a ketogenic diet. ${ }^{85,86}$ Evidence is accumulating that vigabatrin, an inhibitor of $\gamma$-aminobutyric acid transaminase, is the anticonvulsant medication of choice for patients with TS. In a comprehensive literature review, 73 of 77 patients with infantile spasms and TS attained complete resolution of seizures when treated with vigabatrin alone..$^{30}$ If anticonvulsant medications and dietary modifications are not effective, then neurosurgical intervention can be considered. When selecting patients who will most likely benefit from surgery, physicians must use carefully conducted preoperative electroencephalographic studies to localize an epileptogenic focus to a discrete cortical lesion. ${ }^{29,73,74}$ Resection of such electrically localized seizure foci completely eliminates seizures in 25 to $69 \%$ of preselected patients and significantly reduces seizure frequency in the remaining ones. $4,6,7,51,56$

Factors that predict a favorable response to surgery include unifocal seizures and mild degrees of cognitive impairment. ${ }^{46}$ The multifocal distribution of brain lesions in patients with TS may render the search for a safe surgical target unfeasible. If a single seizure focus cannot be identified or if the focus localizes to eloquent cortex, then placement of a vagal nerve stimulator may be an effective surgical alternative. In one series, vagal nerve stimulation reduced seizure frequency by $50 \%$ in nine of 10 patients. ${ }^{69}$

Another indication for neurosurgical treatment of patients with TS is decompression of a space-occupying lesion, usually a SEGA causing obstructive hydrocephalus at the foramen of Monro. Microsurgical treatment of these tumors is indicated for patients in whom there are no medical comorbidities or psychosocial contraindications. Giant cell astrocytomas are slow-growing, noninvasive tumors, so gross-total resection is curative. In one series of $12 \mathrm{pa}-$ tients, no tumor recurred postsurgically after a mean followup duration of 52 months. ${ }^{21}$ When planning the surgical approach to the anterior third ventricle in a patient with TS, neurosurgeons must be aware of coexisting developmental anomalies of the brain. For example, agenesis of the corpus callosum, which can be associated with interdigitation of cortical tissue between opposing surfaces of the cerebral hemispheres, can make interhemispheric approaches difficult and hazardous, because of the need for tedious dissection through ill-defined tissue planes and uncertainty about the location of pericallosal and callosomarginal arteries.

\section{Future Strategies: Targeting Akt and mTOR Signaling}

The central role of hyperactive PI3K signaling in TS suggests that pharmacological inhibition of the PI3K pathway might be a rational treatment strategy, at least for associated malignant tumors. A logical treatment target is mTOR itself. As detailed in the review by Bjornsti and Houghton, ${ }^{9}$ exposure of tumor cells to rapamycin, a macrolide antibiotic agent, markedly suppresses growth of tumor cells in culture by interfering with the ability of mTOR to activate mRNA translational mechanisms. Rapamycin was first developed as an antifungal drug, but when it was found to be a potent immunosuppressant, this discovery led to approval by the US Food and Drug Administration for rapamycin use to prevent rejection of transplanted organs.

Rapamycin reduces tumor cell proliferation in the Eker rat, a naturally occurring genetic model of TS resulting from a $T s c 2$ gene mutation. ${ }^{52,92}$ Rapamycin and several chemical analogs are now being tested in human clinical trials, and evidence is accumulating that they are effective anticancer agents (see literature reviews by Rowinsky ${ }^{75}$ and Sawyers ${ }^{77}$ ). Reported toxic effects have been mild and include cutaneous reactions, transitory myelosuppression, and reversible hepatic dysfunction. A potential problem involving mTOR inhibitors is the inhibitory feedback loop from mTOR to Akt. Blocking mTOR signaling with rapamycin could promote tumor proliferation by removing the physiological constraint to Akt signaling imposed by mTOR. ${ }^{62}$ Considering this possibility, it might be necessary to combine rapamycin with an inhibitor of Akt or PI3K to maximize cell growth suppression.

\section{CONCLUSIONS}

Tuberous sclerosis is an outstanding example of a complex genetic disorder whose pathogenesis is being elucidated by application of molecular methods to human disease. In the picture that is emerging, mutations in one of two tumor suppressor genes, $T S C 1$ or $T S C 2$, perturb control of cell growth in the central nervous system by activating the PI3K signal transduction pathway. Further research is likely to resolve the paradox that malignant cancers seldom arise in patients with TS, even though the cell signaling molecules involved are key mediators of cancer cell growth.

\section{References}

1. Al-Saleem T, Wessner LL, Scheithauer BW, et al: Malignant tumors of the kidney, brain, and soft tissues in children and young adults with the tuberous sclerosis complex. Cancer 83: 2208-2216, 1998

2. Astrinidis A, Henske EP: Aberrant cellular differentiation and migration in renal and pulmonary tuberous sclerosis complex. J Child Neurol 19:710-715, 2004

3. Au KS, Williams AT, Gambello MJ, et al: Molecular genetic basis of tuberous sclerosis complex: from bench to bedside. J Child Neurol 19:699-709, 2004

4. Avellino AM, Berger MS, Rostomily RC, et al: Surgical management and seizure outcome in patients with tuberous sclerosis. J Neurosurg 87:391-396, 1997

5. Barkovich AJ, Gressens P, Evrard P: Formation, maturation, and disorders of brain neocortex. AJNR Am J Neuroradiol 13:423-446, 1992

6. Baumgartner JE, Wheless JW, Kulkarni S, et al: On the surgical treatment of refractory epilepsy in tuberous sclerosis complex. Pediatr Neurosurg 27:311-318, 1997

7. Bebin EM, Kelly PJ, Gomez MR: Surgical treatment for epilepsy in cerebral tuberous sclerosis. Epilepsia 34:651-657, 1993

8. Bernauer TA: The radial bands sign. Radiology 212:761-762, 1999

9. Bjornsti MA, Houghton PJ: The TOR pathway: a target for cancer therapy. Nat Rev Cancer 4:335-348, 2004

10. Bolton PF, Park RJ, Higgins JN, et al: Neuro-epileptic determinants of autism spectrum disorders in tuberous sclerosis complex. Brain 125:1247-1255, 2002

11. Bonnin JM, Rubinstein LJ, Papasozomenos SC, et al: Subependymal giant cell astrocytoma. Significance and possible cytogenetic implications of an immunohistochemical study. Acta Neuropathol (Berl) 62:185-193, 1984

12. Braffman BH, Bilaniuk LT, Naidich TP, et al: MR imaging of tuberous sclerosis: pathogenesis of this phakomatosis, use of 
gadopentetate dimeglumine, and literature review. Radiology 183:227-238, 1992

13. Brown JM: Tuberose sclerosis with malignant astrocytoma. Med J Aust 1:811-814, 1975

14. Cantley LC: The phosphoinositide 3-kinase pathway. Science 296: 1655-1657, 2002

15. Carbonara C, Longa L, Grosso E, et al: Apparent preferential loss of heterozygosity at TSC2 over TSC1 chromosomal region in tuberous sclerosis hamartomas. Genes Chromosomes Cancer 15:18-25, 1996

16. Castro M, Shepherd CW, Gomez MR, et al: Pulmonary tuberous sclerosis. Chest 107:189-195, 1995

17. Cheadle JP, Reeve MP, Sampson JR, et al: Molecular genetic advances in tuberous sclerosis. Hum Genet 107:97-114, 2000

18. Chou TM, Chou SM: Tuberous sclerosis in the premature infant: a report of a case with immunohistochemistry on the CNS. Clin Neuropathol 8:45-52, 1989

19. Christophe C, Sekhara T, Rypens F, et al: MRI spectrum of cortical malformations in tuberous sclerosis complex. Brain Dev 22:487-493, 2000

20. Crino PB, Henske EP: New developments in the neurobiology of the tuberous sclerosis complex. Neurology 53:1384-1390, 1999

21. Cuccia V, Zuccaro G, Sosa F, et al: Subependymal giant cell astrocytoma in children with tuberous sclerosis. Childs Nerv Syst 19:232-243, 2003

22. Curatolo P, Verdecchia M, Bombardieri R: Tuberous sclerosis complex: a review of neurological aspects. Eur J Paediatr Neurol 6:15-23, 2002

23. Dabora SL, Jozwiak S, Franz DN, et al: Mutational analysis in a cohort of 224 tuberous sclerosis patients indicates increased severity of TSC2, compared with TSC1, disease in multiple organs. Am J Hum Genet 68:64-80, 2001

24. Finkelstein R: Advances in tuberous sclerosis complex research: the October 1, 2003, Child Neurology Society Workshop. J Child Neurol 19:734-735, 2004

25. Fleury P, de Groot WP, Delleman JW, et al: Tuberous sclerosis: the incidence of sporadic cases versus familial cases. Brain Dev 2:107-117, 1980

26. Gomez MR: Phenotypes of the tuberous sclerosis complex with a revision of diagnostic criteria. Ann N Y Acad Sci 615:1-7, 1991

27. Green AJ, Johnson PH, Yates JR: The tuberous sclerosis gene on chromosome 9q34 acts as a growth suppressor. Hum Mol Genet 3:1833-1834, 1994

28. Green AJ, Smith M, Yates JR: Loss of heterozygosity on chromosome $16 \mathrm{p} 13.3$ in hamartomas from tuberous sclerosis patients. Nat Genet 6:193-196, 1994

29. Guerreiro MM, Andermann F, Andermann E, et al: Surgical treatment of epilepsy in tuberous sclerosis: strategies and results in 18 patients. Neurology 51:1263-1269, 1998

30. Hancock E, Osborne JP: Vigabatrin in the treatment of infantile spasms in tuberous sclerosis: literature review. J Child Neurol 14:71-74, 1999

31. Hay N, Sonenberg N: Upstream and downstream of mTOR. Genes Dev 18:1926-1945, 2004

32. Hehman K, Norrell H, Howieson J: Subependymomas of the septum pellucidum. Report of two cases. J Neurosurg 29: 640-644, 1968

33. Henske EP, Neumann HP, Scheithauer BW, et al: Loss of heterozygosity in the tuberous sclerosis (TSC2) region of chromosome band 16p13 occurs in sporadic as well as TSC-associated renal angiomyolipomas. Genes Chromosomes Cancer 13: 295-298, 1995

34. Henske EP, Scheithauer BW, Short MP, et al: Allelic loss is frequent in tuberous sclerosis kidney lesions but rare in brain lesions. Am J Hum Genet 59:400-406, 1996

35. Hirose T, Scheithauer BW, Lopes MB, et al: Tuber and subependymal giant cell astrocytoma associated with tuberous sclerosis: an immunohistochemical, ultrastructural, and immuno- electron and microscopic study. Acta Neuropathol (Berl) 90: 387-399, 1995

36. Hopewell JW: The subependymal plate and the genesis of gliomas. J Pathol 117:101-103, 1975

37. Houser OW, Shepherd CW, Gomez MR: Imaging of intracranial tuberous sclerosis. Ann N Y Acad Sci 615:81-93, 1991

38. Hunt A: Development, behaviour and seizures in 300 cases of tuberous sclerosis. J Intellect Disabil Res 37 (Pt 1):41-51, 1993

39. Hunt A, Lindenbaum RH: Tuberous sclerosis: a new estimate of prevalence within the Oxford region. J Med Genet 21:272-277, 1984

40. Hyman MH, Whittemore VH: National Institutes of Health consensus conference: tuberous sclerosis complex. Arch Neurol 57:662-665, 2000

41. Ilgren EB, Westmoreland D: Tuberous sclerosis: unusual associations in four cases. J Clin Pathol 37:272-278, 1984

42. Inoki K, Corradetti MN, Guan KL: Dysregulation of the TSCmTOR pathway in human disease. Nat Genet 37:19-24, 2005

43. Inoki K, Zhu T, Guan KL: TSC2 mediates cellular energy response to control cell growth and survival. Cell 115:577-590, 2003

44. Inoue $Y$, Nemoto $Y$, Murata R, et al: CT and MR imaging of cerebral tuberous sclerosis. Brain Dev 20:209-221, 1998

45. Iwasaki Y, Yoshikawa H, Sasaki M, Sugai K, et al: Clinical and immunohistochemical studies of subependymal giant cell astrocytomas associated with tuberous sclerosis. Brain Dev 12: 478-481, 1990

46. Jarrar RG, Buchhalter JR, Raffel C: Long-term outcome of epilepsy surgery in patients with tuberous sclerosis. Neurology 62:479-481, 2004

47. Jones AC, Daniells CE, Snell RG, et al: Molecular genetic and phenotypic analysis reveals differences between TSC1 and TSC2 associated familial and sporadic tuberous sclerosis. Hum Mol Genet 6:2155-2161, 1997

48. Jones AC, Shyamsundar MM, Thomas MW, et al: Comprehensive mutation analysis of TSC1 and TSC2-and phenotypic correlations in 150 families with tuberous sclerosis. Am J Hum Genet 64:1305-1315, 1999

49. Jozwiak S, Kwiatkowski D, Kotulska K, et al: Tuberin and hamartin expression is reduced in the majority of subependymal giant cell astrocytomas in tuberous sclerosis complex consistent with a two-hit model of pathogenesis. J Child Neurol 19: 102-106, 2004

50. Jozwiak S, Schwartz RA, Janniger CK, et al: Usefulness of diagnostic criteria of tuberous sclerosis complex in pediatric patients. J Child Neurol 15:652-659, 2000

51. Karenfort M, Kruse B, Freitag H, et al: Epilepsy surgery outcome in children with focal epilepsy due to tuberous sclerosis complex. Neuropediatrics 33:255-261, 2002

52. Kenerson HL, Aicher LD, True LD, et al: Activated mammalian target of rapamycin pathway in the pathogenesis of tuberous sclerosis complex renal tumors. Cancer Res 62:5645-5650, 2002

53. Knudson AG Jr: Mutation and cancer: statistical study of retinoblastoma. Proc Natl Acad Sci U S A 68:820-823, 1971

54. Kobayashi T, Minowa O, Kuno J, et al: Renal carcinogenesis, hepatic hemangiomatosis, and embryonic lethality caused by a germ-line Tsc2 mutation in mice. Cancer Res 59:1206-1211, 1999

55. Kobayashi T, Minowa O, Sugitani Y, et al: A germ-line Tscl mutation causes tumor development and embryonic lethality that are similar, but not identical to, those caused by Tsc 2 mutation in mice. Proc Natl Acad Sci U S A 98:8762-8767, 2001

56. Koh S, Jayakar P, Dunoyer C, et al: Epilepsy surgery in children with tuberous sclerosis complex: presurgical evaluation and outcome. Epilepsia 41:1206-1213, 2000

57. Koprowski C, Rorke LB: Spinal cord lesions in tuberous sclerosis. Pediatr Pathol 1:474-480, 1983

58. Kwiatkowski DJ, Zhang H, Bandura JL, et al: A mouse model 
of TSC1 reveals sex-dependent lethality from liver hemangiomas, and up-regulation of p70S6 kinase activity in Tsc1 null cells. Hum Mol Genet 11:525-534, 2002

59. Lagos JC, Holman CB, Gomez MR: Tuberous sclerosis: neuroroentgenologic observations. Am J Roentgenol Radium Ther Nucl Med 104:171-176, 1968

60. Langkau N, Martin N, Brandt R, et al: TSC1 and TSC2 mutations in tuberous sclerosis, the associated phenotypes and a model to explain observed TSC1/ TSC2 frequency ratios. Eur J Pediatr 161:393-402, 2002

61. Lopes MB, Altermatt HJ, Scheithauer BW, et al: Immunohistochemical characterization of subependymal giant cell astrocytomas. Acta Neuropathol (Berl) 91:368-375, 1996

62. Manning BD, Logsdon MN, Lipovsky AI, et al: Feedback inhibition of Akt signaling limits the growth of tumors lacking Tsc2. Genes Dev 19:1773-1778, 2005

63. McLaurin RL, Towbin RB: Tuberous sclerosis: diagnostic and surgical considerations. Pediatr Neurosci 12:43-48, 1985

64. Nagib MG, Haines SJ, Erickson DL, et al: Tuberous sclerosis: a review for the neurosurgeon. Neurosurgery 14:93-98, 1984

65. Nakamura Y, Becker LE: Subependymal giant-cell tumor: astrocytic or neuronal? Acta Neuropathol (Berl) 60:271-277, 1983

66. Niida Y, Lawrence-Smith N, Banwell A, et al: Analysis of both TSC1 and TSC2 for germline mutations in 126 unrelated patients with tuberous sclerosis. Hum Mutat 14:412-422, 1999

67. Onda H, Lueck A, Marks PW, et al: Tsc2(+/-) mice develop tumors in multiple sites that express gelsolin and are influenced by genetic background. J Clin Invest 104:687-695, 1999

68. Osborne JP, Fryer A, Webb D: Epidemiology of tuberous sclerosis. Ann N Y Acad Sci 615:125-127, 1991

69. Parain D, Penniello MJ, Berquen P, et al: Vagal nerve stimulation in tuberous sclerosis complex patients. Pediatr Neurol 25: 213-216, 2001

70. Povey S, Burley MW, Attwood J, et al: Two loci for tuberous sclerosis: one on 9q34 and one on 16p13. Ann Hum Genet 58 (Pt 2):107-127, 1994

71. Richardson EP Jr: Pathology of tuberous sclerosis. Neuropathologic aspects. Ann N Y Acad Sci 615:128-139, 1991

72. Roach ES, Gomez MR, Northrup H: Tuberous sclerosis complex consensus conference: revised clinical diagnostic criteria. J Child Neurol 13:624-628, 1998

73. Romanelli P, Najjar S, Weiner HL, et al: Epilepsy surgery in tuberous sclerosis: multistage procedures with bilateral or multilobar foci. J Child Neurol 17:689-692, 2002

74. Romanelli P, Verdecchia M, Rodas R, et al: Epilepsy surgery for tuberous sclerosis. Pediatr Neurol 31:239-247, 2004

75. Rowinsky EK: Targeting the molecular target of rapamycin (mTOR). Curr Opin Oncol 16:564-575, 2004

76. Sampson JR, Yates JR, Pirrit LA, et al: Evidence for genetic heterogeneity in tuberous sclerosis. J Med Genet 26:511-516, 1989
77. Sawyers CL: Will mTOR inhibitors make it as cancer drugs? Cancer Cell 4:343-348, 2003

78. Scheig RL, Bornstein P: Tuberous sclerosis in the adult. An unusual case without mental deficiency or epilepsy. Arch Intern Med 108:789-795, 1961

79. Sepp T, Yates JR, Green AJ: Loss of heterozygosity in tuberous sclerosis hamartomas. J Med Genet 33:962-964, 1996

80. Sharma M, Ralte A, Arora R, et al: Subependymal giant cell astrocytoma: a clinicopathological study of 23 cases with special emphasis on proliferative markers and expression of p53 and retinoblastoma gene proteins. Pathology 36:139-144, 2004

81. Sima AA, Robertson DM: Subependymal giant-cell astrocytoma. Case report with ultrastructural study. J Neurosurg 50:240-245, 1979

82. Smalley SL, Tanguay PE, Smith M, et al: Autism and tuberous sclerosis. J Autism Dev Disord 22:339-355, 1992

83. Sparagana SP, Roach ES: Tuberous sclerosis complex. Curr Opin Neurol 13:115-119, 2000

84. Sullivan EJ: Lymphangioleiomyomatosis: a review. Chest 114: 1689-1703, 1998

85. Thiele EA: Assessing the efficacy of antiepileptic treatments: the ketogenic diet. Epilepsia 44 Suppl 7:26-29, 2003

86. Thiele EA: Managing epilepsy in tuberous sclerosis complex. J Child Neurol 19:680-686, 2004

87. Tien RD, Hesselink JR, Duberg A: Rare subependymal giantcell astrocytoma in a neonate with tuberous sclerosis. AJNR Am J Neuroradiol 11:1251-1252, 1990

88. Trombley IK, Mirra SS: Ultrastructure of tuberous sclerosis: cortical tuber and subependymal tumor. Ann Neurol 9:174-181, 1981

89. van Slegtenhorst M, Verhoef S, Tempelaars A, et al: Mutational spectrum of the TSC 1 gene in a cohort of 225 tuberous sclerosis complex patients: no evidence for genotype-phenotype correlation. J Med Genet 36:285-289, 1999

90. Vigliano P, Canavese C, Bobba B, et al: Transmantle dysplasia in tuberous sclerosis: clinical features and surgical outcome in four children. J Child Neurol 17:752-758, 2002

91. Waga S, Yamamoto Y, Kojima T, et al: Massive hemorrhage in tumor of tuberous sclerosis. Surg Neurol 8:99-101, 1977

92. Yeung RS, Katsetos CD, Klein-Szanto A: Subependymal astrocytic hamartomas in the Eker rat model of tuberous sclerosis. Am J Pathol 151:1477-1486, 1997

Manuscript received November 28, 2005.

Accepted in final form December 8, 2005.

Address reprint requests to: Daniel W. Fults, M.D., Department of Neurosurgery, 30 North 1900 East, Salt Lake City, Utah 841322303. email: daniel.fults@hsc.utah.edu. 